\title{
Executive Guidelines for Selecting Consultants
}

\author{
Ralph Gallay ${ }^{1}$ \\ ${ }^{1}$ College of Business Administration, Rider University, Lawrenceville, New Jersey, USA \\ Correspondence: Dr. Ralph Gallay, Rider University, 2083 Lawrenceville Road, Lawrenceville, New Jersey, \\ 08648, USA. Tel: 1-609-895-5546. E-mail: gallay@rider.edu
}

Received: January 10, 2013 Accepted: January 29, 2013 Online Published: March 13, 2013

doi:10.5539/ijbm.v8n8p41

URL: http://dx.doi.org/10.5539/ijbm.v8n8p41

\begin{abstract}
This research investigates issues regarding the selection of corporate and institutional consultants. There is considerable information to assist those who conduct research, but little to facilitate the selection of others who perform it. This study integrates ideas found in the literature with those of the researcher who has been a consultant and a client, together with empirically generated executive input. The author conducts a series of personal interviews with corporate and institutional individuals on the client-consultant interface. The information comes from publicly-held and privately-owned organizations in both profit and not-for-profit sectors. The findings lead to an improved understanding of how consulting efficiencies can be enhanced.
\end{abstract}

Keywords: hiring a consultant, selecting a consultant, part-time employee

\section{Introduction}

\subsection{Goals and Significance of the Project}

The goal of this project is to expand the scholarly literature on the client-consultant relationship by focusing on guidelines that are used to select and evaluate consultants across different industries among both profit and not-for-profit sectors. This particular paper pertains to the selection process alone. Much of the literature on this subject at the time of this research is somewhat dated or anecdotal in its treatment of the subject, written mainly as non-scholarly short articles of interest in trade magazines. This study is designed as a literature-based, empirical, descriptive research inquiry.

\subsection{Project Direction}

Most texts on the subject of research methodology focus on design and implementation. There is a scarcity of published information pertaining to the selection of consultants who perform research on behalf of a client. Few companies have the staff with both the qualifications and time to manage critical unstructured requirements (Messmer, 1999). In such cases consultants are needed, especially when projects are of limited duration, require intense time commitments, or require otherwise unavailable specialized skill (Ibid.). As a result approximately eighty-five percent of executives are reported to believe that consultants are necessary for their business and in fact, have used them (Cohen, 1999).

It is the objective of this study to develop more current and relevant guidelines by which consultants can be selected. This inquiry crosses diverse fields of consulting activity. Both corporate and institutional organizations have been considered, as well as a range of activities among industry sectors within those areas. Additionally, profit and not-for-profit centers have been included. Even professional practices and family businesses are prime candidates for consulting engagements (Dennis, 1999). The objective is to develop sufficiently new and important knowledge on the subject.

\section{Literature Review}

At the time of this study, a review of the relevant literature on the subject of the client-consultant relationship revealed mostly anecdotal findings. It appeared clear that this was a subject worthy of a more formal, scholarly inquiry. As stated, methodology herein consisted of a series of executive depth interviews with corporate and institutional individuals who interface with consultants. Twenty interviews were conducted. Through these sessions, sufficient information was gathered to develop meaningful and informative findings. Several avenues of inquiry emerged from the relevant literature. These issues form the basis of this project's investigations and are set out in the following sections. 


\subsection{Search Process}

How do clients select and solicit bids from prospective consultants (Meyers \& Lubliner, 1998)? Perhaps an effort is made to publicize the need over a large number of possible contenders, after which there may be a whittling down process narrowing the field of potential consultants to a few front runners (Barnett, 1999). Or the client company might seek speculative proposals from more than one consultant simultaneously, with a view towards selecting one (Meyers \& Lubliner, 1998). They also feel the practice of soliciting multiple proposals without payment may be harmful in that consultants might feel such "contests" are unrewarding and are not best suited to a full understanding of a client's strategy.

\subsection{Criteria Sought}

Is accessibility to and control over the researcher or perhaps cost, a deciding issue in the selection of consultants (Meyers \& Lubliner, 1998)? How desired consultants are approached is also an important consideration, such as on the basis of personal knowledge or hearsay information (Barnett, 1999). The size of a consulting firm may also be important. A larger firm may offer a wider variety of experiences and provide a broader range of skills according to Meyers and Lubliner (1998). A smaller one however, may offer more specifically suited as well as more personal service (Ibid.).

\subsection{Selecting the Consultant}

Who within the client firm makes the selection of a consultant? Perhaps it is done on the basis of a hierarchical management structure, or the individual who will have the most contact with the consultant makes the choice. Senior level managers should be involved in the decision and selection according to Messmer (1999), but all too often, the company or individual that contracts the service has little idea of what to look for (Barnett, 1999). There are many other incidental issues to consider that bear on this point, such as whether the consultant will have a title, who will work with him/her, who will supervise him/her, where will he/she physically be located (Messmer 1999).

\subsection{Status of the Consultant}

Do more renowned consulting services have an advantage in securing a contract over the less well-known and is their advice accepted less critically? It is not known what exactly determines the status of a consultant. Messmer (1999) suggests clients have a choice between beginners or experienced executives who may have left a traditional full-time job. Barnett (1999) suggests that a consultant's location may be a factor. Perhaps location is relevant in that a "big-city" consultant may have a more successful aura than one practicing from a home-office in the suburbs.

\subsection{Qualifications of the Consultant}

To what extent must consultants demonstrate expertise in a specific product or service area? Dennis (1999) feels that consultants must establish credentials that demonstrate depth of knowledge in specialty areas that they stick to rather than being generalists. On the other hand, Everett (1997) is not sure whether consultants are selected based on their familiarity with specific techniques, or their general understanding of broad strategic issues. One would think it to be important that the client and the consultant have a clearly defined and understood formulation of the problem to be solved. Companies need to know exactly why they are contacting a consultant in the first place (Cohen, 1999) and increasingly, consultants may be providing more general, rather than specialized problem solution advice to clients (Anonymous, 1999). Meyers and Lubliner (1998) feel that most critical is the professional's ability to understand the client's strategy and to develop appropriate and related problem solutions.

\subsection{Credibility of the Consultant}

Do clients check the background, qualifications, or references of consultants? Dennis (1999) points out that no degree programs or certificates are offered in areas of consulting. As a result a client may want the consultant to itemize any relevant experience, seminars or conferences attended, professional association memberships, speaking engagements, writing, etc. Barnett (1999) agrees that reference checks and on-site meetings are critical, going even further suggesting that the consultant give evidence of stability such as access to outside audited financial statements, other clients, banks, a landlord, as well as the client making a visit to the consultant's site.

\subsection{Contractual Issues}

Are consultants generally required to sign a confidentiality statement? One would think that many companies would be concerned not only with that point, but would want the consultant to agree not to do similar work for competitors. Are consultants expected to sign a contract? 
These are some of the questions and issues pertaining to the selection of consultants that have been pursued during the executive interviews.

\section{Methodology}

\subsection{The Nature of the Design}

The nature of this methodological design was descriptive, yet the investigation had to be open-ended and sufficiently flexible to permit not only these, but other possible avenues of inquiry. Twenty executive depth interviews, each lasting one to two hours, were completed and this in itself was impressive that in all cases, all individuals including top executives at the level of Vice President or even President granted the researcher such exclusive access. Additionally, in every single case respondents allowed the entire interview to be recorded so that it could later be transcribed personally by the researcher, yielding over one hundred and fifty (150) pages of written notes for analysis. For a profile of the types of companies the survey included see Table 1.

Table 1. Profile of those interviewed

\begin{tabular}{l}
\hline Industry/Service Sectors Represented \\
Government (Municipal, State) \\
Research \& Development (Bio-Technology/Pharmaceuticals, Marketing, Scientific) \\
Media (Internet, Print, Radio, Television) \\
Education (K-12, University) \\
Publishing (Business, Financial, News) \\
Restaurant (Management) \\
Health-Care (Home Health, Hospital, In-Patient/Out-Patient Mental Health Services, \\
Long-Term Care \& Rehabilitation) \\
Manufacturing/Marketing (Agricultural Products, Airline Equipment, Chemicals, \\
Consumer Products, Energy Systems, Food Machinery, Health-Care Products, \\
Medical Devices, Nutritionals, Pharmaceuticals)
\end{tabular}

\subsection{The Sample}

The individuals selected for participation came from a broad range of ten publicly held, six privately owned companies and four institutions, fifteen from the for-profit and five from the not-for-profit sectors. Amongst them they employed the services of over two hundred and fifty (250) types of consultants filling a myriad of applications. All but two were located in New Jersey, USA a regional center of major business activity within the country. Certainly many more might have been contacted and in neighboring states, but since only twenty (20) executive interviews were conducted there were more than enough from which to choose in the immediate area. Besides, getting the cooperation form the executives that chose to participate was not an easy task. Considerable planning, searching and convincing had to be done just to line up the twenty that were interviewed. For a complete list of participating companies see Table 2 .

Table 2. Executive interview participants

\begin{tabular}{ll}
\hline Title, Company and Location & Nature of the Business \\
\hline 1. Township Administrator & Non-Profit, \\
Township of Plainsboro, Plainsboro, N.J. & Municipal Government \\
2. Staffing Consultant, Contingent Workforce & For Profit, Privately Owned, \\
Sarnoff Corporation, Princeton, N.J. & Scientific Research \\
3. Chief Administrative Officer & For Profit, Publicly Owned, \\
Total Research Corporation, Princeton, N.J. & Marketing Research \\
4. Assistant Controller & For Profit, Publicly Owned, \\
ABC Television Network, New York, N.Y. & Television Network \\
\hline
\end{tabular}


5. Assistant Superintendent

Finance and Support Services

West Windsor-Plainsboro School District

Princeton Junction, N.J.

6. Editor-in-Chief, Books and Magazines

Bloomberg Publications, Princeton, N.J.

7. Director of Creative Services

Bloomberg Publications, Princeton, N.J.

8. Director of Human Resources

Global Business Services

Bristol Myers Squibb Company, Princeton, N.J.

9. Vice President

Biostatistics, Clinical/Regulatory Operations

The Liposome Company Inc., Princeton, N.J.

10. Vice President, People and Communications Sarnoff Corporation, Princeton, N.J.

11. President, Chief Executive Officer

The Rose Group, Newtown, PA.

12. Manager Central Support

Network and Computer Services

Dow Jones \& Company, Princeton, N.J.

13. Human Relations Manager

Agricultural Products Group R\&D

FMC Corporation, Chemical R\&D Center

Princeton, N.J.

14. Director, Financial Services

Dow Jones \& Company, Princeton, N.J.

15. Vice President

Corporate Business Development

Johnson \& Johnson, New Brunswick, N.J.

16. Corporate Treasurer

Johnson \& Johnson, New Brunswick, N.J.

17. Vice President of Tax

Covance Inc., Princeton, N.J.

18. Vice President, Finance

The Medical Center at Princeton

Princeton, N.J.

19. Assistant Director

New Jersey, Department of the Treasury

Division of Purchase \& Property

Trenton, N.J.

20. Vice President for Finance and Administration

Princeton University, Princeton, N.J.
Non-Profit,

Public Education

For Profit, Privately Owned,

Publishing \& Media Services

For Profit, Privately Owned,

Publishing \& Media Services

For Profit, Publicly Owned,

Diversified Manufacturing/Marketing

For Profit, Publicly Owned,

Fully Integrated Bio-Technology

and Pharmaceuticals R\&D

For Profit, Privately Owned,

Scientific Research

For Profit, Privately Owned,

Restaurant Management

For Profit, Publicly Owned,

Publishing

For Profit, Publicly Owned,

Manufacturing/Chemical Research \& Development

For Profit, Publicly Owned,

Publishing

For Profit, Publicly Owned, World's Largest

Manufacturer and Marketer of Health Care Products

For Profit, Publicly Owned, World's Largest

Manufacturer and Marketer of Health Care Products

For Profit, Publicly Owned,

Contract Drug Research Development Services

Non-Profit, Community Based/Community Directed

Institutional Facility, Health Care Medical Center

Non-Profit,

State Government

Non-Profit, Privately Owned,

Higher Education and Research 


\subsection{The Framework for Analysis}

The interviews were all conducted personally by the author on a face-to-face basis, typically in each executive's office using a survey instrument consisting of approximately seventy (70) questions, each formed to explore specific issues gleaned from the literature and discussed in the previous section. Coding and analysis of the responses followed standard acceptable procedures for such open-ended data. Because of the limited sample size and the open-ended nature of this inquiry, data were not subjected to statistical significance tests, but were analyzed and are presented in a qualitative framework, addressing each of the issues outlined in the literature discussion. Results therefore are purposely expressed in descriptive terms such as most, a majority, etc., rather than by quantitative measures.

\subsection{The Timeframe of the Data Collection and Literature Search}

It is to be noted that all of these interviews were conducted in the summer of 2000. The data were never analyzed until much later. Still, the interviews being that they were with corporate executives have a lasting timeliness to them and offer a valuable insight even now. As such, the study serves as an important investigation into the scholarly issues and managerial attitudes surrounding this topic as of the turn of the century and the beginning of the current millennium. This research therefore, can serve as a benchmark for future archival and comparative studies on the same subject. Certainly more recent literature on this subject has since been published, but that would be the basis of an update, or a second follow-up study to this one. Only the literature sources actually used in this study appear in the reference section.

\section{Findings and Discussion}

\subsection{Qualifying Questions}

Respondents were asked a few qualifying questions to insure the appropriateness of including them in the survey. These included the following issues. All respondents indicated their organization or institution used consultants. The individuals interviewed all had a role in selecting and/or evaluating consultants. Most were involved with the preparation of the contracts specifying legal and consulting terms. Many were the actual supervisors or managers of the prospective consultants. Some networked with other firms or departments within their own company to engage the services of consultants. The range of consulting specialties most sought after, varied considerably. Those mentioned most often included technical designers as well as marketing, advertising, financial, information technology and other general services.

\subsection{Search Process}

As to how consultants were sought, in some cases RFP's (request for proposal) were used, but in most instances consultants who had previously worked at the company or institution and with whom the client had prior successful experiences were hired again. On few occasions consultants had approached the client for interviews, or were made aware of by word of mouth. In most instances, if bids for services were solicited they were done so in a general request for proposal (RFP) and individuals were selected from a list of respondents. Often the same individuals were used over and over again, or selected on the basis of word-of-mouth. While growing in popularity at that time, the Internet to find such individuals was less frequently used. Consulting opportunities in most instances were opened up to as many as might be interested, but in about half the cases, front-runners with prior experience had a selection advantage. Client firms were about equally split as to whether they sought speculative, or invited proposals from more than one consultant at a time with a view towards selecting one. In seeking multiple respondents to file proposals for consulting activity, almost all the clients if they followed this procedure, did so feeling strongly that such contests added competition amongst consultants and seemed to motivate them to submit their best proposals. It was especially true amongst those proposals submitted on speculation, that they were indeed considered to be serious efforts suited to the company's needs.

\subsection{Criteria Sought}

By far, the most important criteria in selecting consultants were their costs, their accessibility, but mainly their expertise and the quality of such individuals. Prior experience with the company was helpful but not a determinant on its own to result in one being rehired. Personal knowledge of the consultant was most important in aiding the selection of an individual, followed up by references. Seldom were selections based primarily on recommendations or hearsay information from others. In the majority of cases, the size of the consulting firm was of little importance, but it did depend on the job and the necessity to have additional members from the consulting team's company available if needed. Certainly there was a popular belief that larger consulting firms offered a wider variety of experience and skills, but not necessarily in all cases. A large majority felt that smaller consulting firms could offer more specialized and personal service, but again it depended on the project as well 
as the number of other commitments held by the consultant. In looking for a consultant, in by far the greatest number of instances, the qualities that were required related to the person's expertise and history of prior experiences. Often this was a team effort of determination in the selection process.

\subsection{Selecting the Consultant}

As to the hiring of consultants in most instances it was a senior project director that participated in the selection of a consultant, but in almost an equal number of instances it was the relevant department which handled the process. In fewer cases, it was a team effort among several individuals and departments. The final decision on selection of the consultant seemed to be mostly a team effort rather than top management or by the individual who would have the most contact with the consultant, but it varied with the project. With regard to who would work with or supervise the consultant, in most cases this was known in advance and depended on the nature of the work or was often decided by team input. In other instances the consultant and/or the project leader provided input in this matter.

\subsection{Status of the Consultant}

Rarely would consultants have a specific title while engaged with the client so this had no influence on their image in the selection process. As to the reputation of the consulting firm providing such services most admitted that those which were most renowned had an advantage over the lesser known, but a large number indicated that all were considered equal in this regard. In some instances it depended on the project as to the reputation of the consulting firm selected. In some instances advice from a well known consultant was viewed less critically than that from a novice, but in the majority of cases, whether renowned or not, advice from all consultants was treated with equal consideration. The status of a consultant was mostly dependent primarily on his/her quality of service and reputation. Several indicated that schooling and prior experience also had an effect on a consultant's status, but a few indicated this image not to be important. While not overly responsive to this issue, for the most part hiring firms tended to shy away from beginning consultants, opting for those who were most experienced. Almost all indicated the physical location of the consultant made no difference to them and that "big city" consultants had no advantage over those practicing from a home-office in the suburbs.

\subsection{Qualifications of the Consultant}

It was expected in almost all cases that a consultant would be able to demonstrate expertise in a product or service area. While most indicated it depended on the project as to whether one looked for depth of expertise in a specialty area, or a broad strategic knowledge as a generalist, the emphasis when it mattered was markedly on the former. In an almost equal number of instances, the company either had a clearly defined problem prior to the consultant being hired, or they worked on it together developing it as the relationship proceeded, but it depended on the situation. In an equal number of instances, consultants with either a specialized problem-solving expertise, or those with a general ability were sought. Most felt it was necessary for a consultant to understand the client's overall strategy in order to develop tactically-related solutions to problems, but in a number of cases some felt this was not always a requirement.

\subsection{Credibility of the Consultant}

In almost all instances the client checked the background, qualifications and references of consultants. In doing so, client firms were primarily looking for relevant experience and previous related employment activities and to a much lesser extent, seminars or conferences attended, or writing. Rarely, but on a few occasions would a client seek evidence of stability in a consultant in the form of outside audited financial statements, banks, landlords, etc. As to where the consultant was to be located during the course of his/her work it seemed to be equally split between working in the office of the hiring firm or out of the office, but in a few cases the choice was left up to the consultant. Regardless, in most instances, clients considered visiting the consultant's site at his/her office as a way of verifying his/her credibility, but quite a large number did not feel this to be necessary.

\subsection{Contractual Issues}

Most firms required the consultant to sign a confidentiality statement. A few did not. Seldom was it asked of a consultant to refrain from doing similar work with a competitor. The large majority did not make such requests, but a few did. In the very large majority of cases clients required the consultants to sign a contractual agreement.

\section{Conclusions}

\subsection{Overall}

This research has investigated many questions that have been raised in the literature as being meaningful and important in the selection of consultants. Results have been categorized along seven main dimensions. Although 
the approach was qualitative and based on a rather limited but highly selective series of open-ended executive depth interviews, the findings are extremely rewarding. The fact that twenty corporate and institutional individuals, many at very high levels, shared their views which are reported here made for a unique insight to their thinking and decision-making.

\subsection{Specific Guidelines for Selecting Consultants}

The findings yielded the following guidelines used in a majority of instances by executives selecting consultants:

- Consultants who had previously worked at the company or institution and with whom the client had prior successful experiences were hired again.

- If bids for services were solicited they were done so in a general request for proposal (RFP).

- Often the same individuals were used over and over again, or selected on the basis of word-of-mouth.

- The most important criteria in selecting consultants were their costs, their accessibility, but mainly their expertise and the quality of such individuals.

- $\quad$ Personal knowledge of the consultant was most important in aiding the selection of an individual.

- The size of the consulting firm was of little importance, but it did depend on the job.

- In looking for a consultant, in by far the greatest number of instances, the qualities that were required related to the person's expertise and history of prior experiences.

- Often, selection of a consultant was a team effort of determination early on in the process.

- In most instances it was a senior project director that participated in the selection of a consultant.

- The final decision on selection of the consultant seemed to be mostly a team effort.

- With regard to who would work with or supervise the consultant, in most cases this was known in advance and depended on the nature of the project.

- Rarely would consultants have a specific title while engaged with the client,

- $\quad$ Those consultants who were most renowned had an advantage over the lesser known.

- Whether renowned or not, advice from all consultants was treated with equal consideration.

- The status of a consultant was mostly dependent on his/her quality of service and reputation.

- Schooling and prior experience also had an effect on a consultant's status.

- Clients tended to shy away from beginning consultants, opting for those who were most experienced.

- $\quad$ Physical location of the consultant made no difference.

- Consultants were expected to be able to demonstrate expertise in a product or service area.

- When it mattered, depth of expertise in a specialty area was emphasized, rather than a broad strategic knowledge as a generalist.

- It was felt to be necessary for a consultant to understand the client's overall strategy in order to develop tactically-related solutions to problems.

- Almost always, clients checked the background, qualifications and references of consultants.

- Clients primarily looked for relevant experience and previous related employment activities.

- A consultant's location during the course of his/her work was equally split between working in the office of the client or out of their own office.

- Most firms required consultants to sign a confidentiality statement.

- Seldom was it asked of a consultant to refrain from doing similar work with a competitor.

- In the large majority of cases clients required the consultants to sign a contractual agreement.

\subsection{Limitations and Future Research}

The findings of this study offer numerous leads for more extensive research studies that can be based on and related to this work. Some ideas follow. As previously noted, this study was done in the year 2000 as a qualitative, exploratory investigation of issues raised in the literature at that time. As such, it serves as a benchmark study to which current and future research can be compared. New investigations might be based on up-dates in the literature and the formation of additional hypotheses based on these findings and new 
expectations. Data obtained from the implementation of structured questionnaires would allow significance testing, a more detailed investigation and more definitive conclusions on a range of issues dealing with comparisons across consulting services, or those who use them, or an archival study to compare these results to those obtained in the future.

\section{References}

Anonymous. (1999). Short Courses in Management Consultancy. Management Accounting-London, 77(2), 7.

Barnett, D. (1999). What to Look for in a TPA (Third-Party Administrator). Business \& Health, 17(2), 25-27.

Cohen, A. (1999). Are Consultants Worth It? Sales \& Marketing Management, 151(9), 32-42.

Dennis, A. (1999). Consulting to Lawyers and Families. Journal of Accountancy, 187(3), 68-71.

Everett, J. B. (1997). The Missing Link. Marketing Research: A Magazine of Management \& Applications, 9(1), 33-36.

Messmer, M. (1999). Getting the Most out of Consulting Arrangements. Strategic Finance, 81(3), 10-12.

Meyers, H. M., \& Lubliner, M. J. (1998). Designing the Designer. Beverage World, 117(1664), 78-82.

State of New Jersey. (1998). Commodity Code Directory: a comprehensive listing of products and services bought by the State of New Jersey (pp. 29-30). Department of the Treasury, Division of Purchase \& Property, Purchase Bureau. 